\title{
Laparoscopic cholecystectomy in children
}

\author{
Bibza J, Sykora L, Cingel V, Duchaj B, Babala J, Kralik R, Horn F, Jager R, Sandorova D \\ Department of Pediatric Surgery, Comenius University Children's Hospital, Bratislava, Slovakia. \\ bibza.jarko@gmail.com
}

\begin{abstract}
In 95 children (age 6-18 y) treated for gallstones between 2002-2010, 95 laparoscopic cholecystectomies were carried out. Symptomatic cholecystolithiasis was the indication for laparoscopic cholecystectomy in most of the cases. In three patients, there was a conversion to open cholecystectomy. Postoperative complications due to failure of bile drainage arose in three patients. Restored bile drainage was secured for two biliodigestive anastomosis. Bile leak in a third patient solved a temporary biliary stent. Laparoscopic cholecystectomy is the gold standard for gallstones (Ref. 8). Full Text in PDF www.elis.sk.

Key words: gallstones, laparoscopic cholecystectomy, cholecystolithiasis, bile drainage.
\end{abstract}

The benefits of laparoscopic cholecystectomy include decreased pain and ileus after surgery, shortened hospitalization, and improved cosmetic (1). Oak et al. (2) arrived to the same conclusion when comparing traditional cholecystestomy with laparoscopic cholecystectomy.

\section{Materials and methods}

The authors analysed a group of patients, in whom laparoscopic cholecystectomy was performed in the nine year period from January 2002 to December 2010. Laparoscopic cholecystectomy was performed in 95 patients. In this period, four patients were operated on by a traditional approach - laparotomy and in their cases also splenectomy for hematologic disease (spherocytosis) was performed. Papandreou et al (3) operated 54 children in the age of 14 months to 15 years in the period of five years.

By default, antibiotics were not administered as prophylaxis. They were applied in case of a significant pericholecystitis, or in case of a rare perforation of gallbladder when separating it from its supporting area. Some hospitals use standard antibiotics prophylaxis also in elective cholecystectomy (4).

The 3-port approach was mostly sufficient for cholecystectomy $(n=76)$, only in cases of decreased vision in the operated area the 4-port approach was used ( $\mathrm{n}=19)$. Papandreou et al (1) usually introduce 3 ports: an umbilical port for the camera, another in the subxifoid region for the dissector, and a third one in the right lower quadrant for the grasping clamp and the extraction of the gallbladder. As a standard practice, after preparation of $d$. cysticus, the authors placed two clips distally (towards the d. choledochus) and one proximally (towards the cholecyst). After disconnection

Department of Pediatric Surgery, Comenius University Children's Hospital, Bratislava, Slovakia

Address for correspondence: J. Bibza, MD, PhD, Department of Pediatric Surgery, Comenius University Children's Hospital, Limbova 1, SK-833 40 Bratislava, Slovakia. of d. cysticus they isolated a. cystica by cutting it off between the two clips. Only exceptionally, a. cystica was not clipped, but interrupted by a bipolar coagulation.

Mobilisation of patients was possible since the 1st day after operation. In older children and in children with overweight or even obesity, mobilisation out of bed was more difficult, starting usually on the 2 nd day after operation.

\section{Results and discussion}

Laparoskopic cholecystectomy was performed in 95 patients. The number of girls $(n=67)$ was more than twice as high as the number of boys ( $n$ 8). The youngest patient in the sample was a 6 -year old girl, the age category of the 18-year old $(n=22)$ formed the biggest group in the sample.

The indications for the operation were subjective difficulties such as biliary colic and abdominal discomfort (,nausea in the area of abdomen“, bloating) in ultrasound detected pathological contents of the gallbladder (lithiasis, biliary mud, polyp). In rare cases, in the presence of subjective difficulties without positive ultrasound pathologic findings in or on gallbladder, a functional examination of gallbladder was indicated. In majority of patients, subjective difficulties were recorded in the interval of 3 months to 1 year. In cases of biliary colic without an obstruction in biliary tract a conservative treatment was preferred (spasmolytics, analgesics) and subsequent surgical approach in quiescence.

St Peter et al. (5) indicated laparoscopic cholecystectomy in more than $2 / 3$ of patients with symptomatic cholecystolithiasis in the sample of 224 children. The second biggest group ( 35 patients) were children with biliary dyskinesis. In the sample of children presented by the authors, the functional examination of gallbladder was performed only in cases of biliary pain without an ultrasound detection of a pathological content in gallbladder.

Almost half of the patients (41\%) suffered by an excessive weight even obesity. Significant relation to necessary operation conversions and complications due to excessive weight even obe- 
sity was not observed. Similar conclusion was presented by Garey et al (6), who had not found a difference in obese patients compared to patients with normal weight in laparoscopic cholecystectomy in the time of operation, in the length of the stay in hospital, nor in the amount of complications. Conversion was performed in three cases. In one case, it was performed due to the findings of phlegmona of gallbladder which occurred after an initial hydrops of gallbladder. In another patient, it was performed because of a hindered view after a tangential lesion in the posterior branch of a. cystica. In the third case, the female patient was shortly after an acute cholecystitis and conversion was indicated because of a difficult identification of anatomic structures during laparoscopy. In cases of an acute inflammation, differentiation of anatomic structures is significantly worse and so conversion of laparoscopy to traditional laparotomic approach is justified. Similarly, Šafránek et al. (7) mentioned an acute cholecystitis as a risk factor justifying the conversion of laparoscopic cholecystectomy. ERCP was performed in three female patients after cholecystectomy due to a defect in bile drainage. In the first case, the bile drainage broke after the cholecytectomy. This was caused by an anomalous anatomic condition, in which accessory biliary duct opened into a cholecyst. After the cholecystectomy, the drainage through biliary duct was removed. The bile drainage was then resumed by hepatic-jejuno Roux-Y anastomosis. In the second patient, due to the obstruction of $d$. choledochus by the clip in anomalous development of $d$. cysticus (d. cysticus spiralis dorsalis) the bile drainage was secured by hepatic-jejuno Roux-Y anastomosis. In the third patient, the bile leak in the area of junction of $d$. cysticus with $d$. hepaticus communis was solved by an introduction of a duodenobiliary stent for 3 months. In all cases, the bile drainage became normal and patients had no problems afterwards.

Due to $\mathrm{n}$ aanomalous development of biliary duct, laparotomic revision and subsequent renewal of bile drainage by biliodigestive anastomosis were performed in two patients. Anatomic variations of vessels and biliary ducts in lig. hepatoduodenal and in porta hepatis are relatively frequent findings. Talpur et al (8) in their sample of 300 patients described a relatively high number of anatomic variations in cystic artery (10.67\%), cystic duct $(4.33 \%)$, right hepatic artery $(2.67 \%)$ and gallbladder $(2 \%)$.
The authors observed a complete healing in the female patient after a minor perforation in the junction of $d$. cysticus and $d$. hepaticus in 3 months. Here they used endoscopic rescue of biliary duct by introduction of a duodeno-biliary stent.

\section{Conclusion}

The authors consider laparoscopic cholecystectomy a safe method for the treatment of cholecystolithiasis in children. Benefits are lower risk of adhesion compared to traditional cholecystectomy, possibility of a thorough revision of abdominal cavity and early mobilisation of children after the operation.

\section{References}

1. Davidoff AM, Branum GD, Murray EA, Chong WK, Ware RE, Kinney TR, Pappas TN, Meyers WC. The technique of laparoscopic cholecystectomy in children. Ann Surg 1992; 215(2): 186-191.

2. Oak SN, Parelkar SV, Akhtar T, Pathak R, Vishwanath N. Role of laparoscopic cholecystectomy in children. J Indian Assoc Pediatr Surg 2005; 10: 92-94.

3. Papandreou E, Gentimi F, Baltogiannis N, Livaditi E, Loukas L, Geroulanos GCH. Laparoscopic cholecystectomy in children: A 5-year experience. Pediatrics 2008; 121 (Suppl 2): S163.

4. Rahman A, Al-Mulhim AS, Abdulatif MM, Ali AM. Laparoscopic cholecystectomy in children with sickle cell disease. Saudi J Gastroenterol 2006; 12: 130-134.

5. St Peter SD, Keckler SJ, Nair A, Andrews WS, Sharp RJ, Snyder CL, Ostlie DJ, Holcomb GW. Laparoscopic cholecystectomy in the pediatric population. J Laparoendosc Adv Surg Tech A 2008; 18 (1): 127-130.

6. Garey CL, Laituri CA, Keckler SJ, Ostlie DJ, Stagg HW, Little DC, St Peter SD. Laparoscopic cholecystectomy in obese and non obese children. J Surg Res 2010; 163 (2): 299-302.

7. Šafránek J, Šebor J Jr, Geiger J. Conversion of laparoscopic cholecystectomy. Rozhl Chir 2002; 81 (5): 236-239.

8. Talpur KA, Laghari AA, Yousfani SA, Malik AM, Memon AI, Khan SA. Anatomical variations and congenital anomalies of extra hepatic biliary system encountered during laparoscopic cholecystectomy. J Pak Med Assoc 2010; 60 (2): 89-93. 